\title{
Expression of Lysozyme and Aquaporins mRNA in Otitis Media
}

\author{
Sung-Ho Kang ${ }^{1}$, Dae-Joon Lim ${ }^{1}$, Bo-Hyung Kim ${ }^{1}$, Myung-Sang Rhu ${ }^{1}$ and Shin-Seok Kang ${ }^{2, \dagger}$

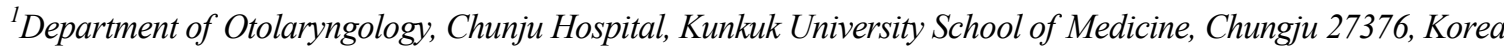 \\ ${ }^{2}$ Chungbuk Veterinary Service Laboratory, Chungju 27336, Korea
}

\begin{abstract}
Lysozyme is known as a key substance of the innate immunity and have antibacterial effect in the mucosal tissues, especially middle ear. Aquaporin (AQP) functions as water movement in the tissue and has been expected to be participated in the inflammatory responses. In the present study, we investigated to reveal association of lysozymes and AQPs in otitis media. The gene expression of lysozyme genes, homo sapiens lysozyme (hLYZ), homo sapiens lysozyme M (hLYZ M), and homo sapiens lysozyme G like-2 (hLYGH), and AQP genes (AQP 0 - AQP 12) were measured from postauricular skin, mastoid mucosa, inflamed mastoid mucosa, and middle ear mucosa. The hLYZ, hLYZ M and hLYGH gene were expressed in mastoid mucosa, inflamed mastoid mucosa, middle ear mucosa. Of AQP genes, all AQP gene except AQP 3 gene were expressed in the tissue of middle ear. Among them, AQP 4, AQP 8, AQP 9, AQP 10, AQP 11 and AQP 12 were highly expressed in the inflamed mastoid mucosa and normal mastoid mucosa $(P<0.001)$. Interestingly, expression levels of AQP 4, AQP 9, and AQP 12 gene were significantly higher in the inflamed mastoid mucosa compared to normal middle ear mucosa $(P<0.05)$. These results suggest that lysozyme and AQPs could be associated with inflammatory response in the middle ear.
\end{abstract}

Key Words: Otitis media, Lysozyme, Aquaporin (AQP), Inflamed mastoid mucosa

\section{INTRODUCTION}

Otitis media is the inflammatory disease of the middle ear. Otitis media is a main reason for doctor visits and the most common cause of hearing loss (Klein, 2000). Otitis media can be classified on the characteristics of the effusion; serous, mucoid, suppurative, which indicates infectious or inflammatory response in the mucosa. The main factors of otitis media are Eustachian tube dysfunction and microbial infection (Rovers et al., 2004). Bacterial infection is likely cause otitis media than viral infection, and the immune response tends to depend on congenital immune mechanisms rather than acquired immunity.
Lysozyme is found in most of tissue of mammals, especially mucosal membrane such as respiratory, digestive and reproductive system as well as middle (Konstan et al., 1982; Prager and Jolles, 1996; Lim et al., 2000; Ganz, 2004), which functions as a key substance of the innate immunity and exhibit bactericidal activity (Park et al., 1992). Lysozyme M is known to exert excellent bactericidal effects against gramnegative bacteria (Markart et al., 2004). Homo sapiens Lysozyme G like-2 (hLYGH) is distributed in ovipara and show bactericidal activity as lysozyme (Kim, 2005; Giacomello et al., 2006).

Aquaporin (AQP), also called waterway, was first reported in 1993 (Agre et al., 1993). Aquaporin is the most rapid piping system that enable water move in a structured way

*Received: May 3, 2018 / Revised: June 20, 2018 / Accepted: June 21, 2018

${ }^{\dagger}$ Corresponding author: Shin-Seok Kang. Chungbuk Veterinary Service Laboratory, 13 Paenggorisan-gil, Chungju-si, Chungchengbuk-do 27336, Korea. Tel: +82-43-220-6311, Fax:+82-43-220-6319, e-mail: newstonek@naver.com

(C) The Korean Society for Biomedical Laboratory Sciences. All rights reserved.

(c) This is an Open Access article distributed under the terms of the Creative Commons Attribution Non-Commercial License (http://creativecommons.org/licenses/by-nc/3.0/) which permits unrestricted non-commercial use, distribution, and reproduction in any medium, provided the original work is properly cited. 
in the tissue cells. Thirteen Aquaporin-related genes, AQP 0 to AQP12 have been reported up to now (Seo and Choi, 2015). The AQP 0 gene is known to be essential to maintain the transparency of the lens in the eye, which has holes to enable water to move within the protein (Nemeth-Cahalan et al., 2013). The AQP 1 gene is inherently present and expressed in the cell membrane of the erythrocyte and kidney, but its expression is not regulated by Vasopressin (Denker et al., 1988). The AQP 2 gene was expressed in the collecting duct of the kidney, and its expression was regulated by Vasopressin. In the starvation state, expression level of AQP 2 gene was decreased (Dibas et al., 1998). AQP 3 and AQP 6 protein are found in the basal cell membrane of renal collecting ducts, where play a role of water excretion (Sasaki et al., 1998). AQP 4 gene was also expressed in the basal cell membrane of the renal collecting duct and was a target of autoimmunity temporally in the neuromyelitis optica (Lennon et al., 2005). AQP 5 is involved in the production of saliva and tear, and also involved in the secretory mechanism of the lungs. The function of AQP 5 is very similar to AQP 0, AQP 2, and AQP 6 (Lee et al., 1996). AQP 7 is involved in the transport of water, glycerol, and urea and AQP 8 is widely distributed in the digestive system (Ishibashi et al., 1997; Elkjaer et al., 2001). AQP 9 is genetically very similar to AQP 3 and AQP 7, and is known to promote the permeability of osmotic pressure and urea transportation. In addition, AQP 9 facilitates immune responses in lymphocytes and neutrophils (Rojek et al., 2007; Moniagal et al., 2007). AQP 10 is found in the human small intestine and appears to have selective absorption and release of water and glycerol in the epithelium of small intestine (Li et al., 2005). AQP 11 distributed in the kidney, liver, testis, and brain, but its exact mechanism is not well known (Gorelick et al., 2006; Saitoa et al., 2018). AQP 12 is present in the acinar cells of the pancreas and is presumed to play a role in the secretion of digestive enzymes (Itoh et al., 2005). In the case of otitis media, it is presumed that the water movement was necessary because a tympanum was found in the middle ear, which contain inflammatory substances.

In the present study, we examined the expression of lysozyme genes, a key substance of innate immunity, in the middle ear. And AQP genes, possible factors of inflammation, were also investigated in the middle ear, and found that most of AQP genes might be associated with inflammatory status in the middle ear.

\section{MATERIALS AND METHODS}

\section{Subjects and specimens}

Specimens were obtained from patients with otitis media who visited the Department of Otorhinolaryngology, Chungju Hospital, Kunkuk University School of Medicine, Chungju, Republic of Korea between August 2015 and July 2017. Ethical approval was obtained from the Institutional Ethics Committee of Kunkun University School of Medicine (KUCH 2015-08-037). All subjects provided written informed consent. The specimens, postauricular skin, mastoid mucosa, inflamed mastoid mucosa and middle ear mucosa were collected and stored at $-70^{\circ} \mathrm{C}$ until used.

\section{Total RNA extraction}

To examine the expression of lysozyme and Aquaporin genes, the total RNA was extracted from specimens using RNAiso Plus (Takara, Japan) according to the manufacturer's instructions. Briefly, approximately $20 \mathrm{mg}$ of tissue was taken and $1 \mathrm{~mL}$ of RNAiso Plus reagent was added to the tissue, and then tissue was completely disrupted using a homogenizer. After adding $200 \mu \mathrm{L}$ of chloroform (Sigma, USA), the mixture was vigorously mixed and centrifuged at $13,000 \mathrm{rpm}$ for 10 minutes using a refrigerated centrifuge (Labogene, Korea). Five hundred $\mu \mathrm{L}$ of the supernatant was removed into a new tube, and the same amount of isopropanol (Sigma, USA) was added, and then mixed gently. The tube was kept at room temperature for 10 minutes, and then centrifuged at 13,000 rpm for 10 minutes. After the supernatant was discarded, the precipitated pellet was rinsed gently with $1 \mathrm{~mL}$ of $70 \%$ ethanol and centrifuged again at 13,000 rpm for 10 minutes. After discarding the supernatant, the pellet was dried at room temperature for 10 minutes and then, dissolved with $30 \mu \mathrm{L}$ of DEPC-treated RNase- and DNasefree water (WEL GENE, Korea). The extracted RNA was kept at $-70^{\circ} \mathrm{C}$ until used. 


\section{Reverse transcription PCR}

Complementary DNA (cDNA) was synthesized using PrimeScript 1st strand cDNA synthesis kit (Takara Clontech, Japan) according to manufacturer's recommendations. In brief, the first mixture containing $1 \mu \mathrm{L}$ of Oligo dT Primer, $1 \mu \mathrm{L}$ of dNTP mixture, $1 \mu \mathrm{L}$ of extracted RNA, $7 \mu \mathrm{L}$ of DEPC-treated RNase- and DNase-free water was incubated at $65^{\circ} \mathrm{C}$ for 5 minutes and immediately chilled on ice. Then, the second mixture containing $4 \mu \mathrm{L}$ of $5 \times$ PrimeScript buffer, $0.5 \mu \mathrm{L}$ of RNase inhibitor, $1 \mu \mathrm{L}$ of PrimeScript RTase, $4.5 \mu \mathrm{L}$ of DEPC-treated water were incubated at $50^{\circ} \mathrm{C}$ for 1 hour and at $95^{\circ} \mathrm{C}$ for 5 minutes.

PCR primers were designed to target lysozyme genes, hLYZ, hLYZ M, hLYGH using the Primer 3 software (http:// frodo.wi.mit.edu/) using the genomic information obtained from NCBI site (Table 1). PCR primers targeting AQP genes were synthesized according to the previous report (Seo and Choi, 2015). As an internal control, primers for $\beta$-actin gene were used.

PCR reaction for amplification was performed using $2 \times$ TOPsimple DyeMix-multi HOT (Enzynomics, Korea). PCR reaction were carried out using SimpleAmp PCR machine (ABI, USA) with the PCR mixture composing of $2 \mu \mathrm{L}$ of cDNA, $0.5 \mu \mathrm{L}$ of each primer, $7 \mu \mathrm{L}$ of DEPC-treated water, and $10 \mu \mathrm{L}$ of $2 \times$ TOPsimple DyeMix-multi HOT (Enzynomix, Korea) in a total volume of $20 \mu \mathrm{L}$. The thermal cycling conditions were 10 minutes at $95^{\circ} \mathrm{C}$, followed by 35 cycles of 30 seconds at $95^{\circ} \mathrm{C}, 30$ seconds at $60^{\circ} \mathrm{C}, 1$ minute at $72^{\circ} \mathrm{C}$, and final extension for 5 minutes at $72^{\circ} \mathrm{C}$. The PCR products were separated by electrophoresis on $1.5 \%$ agarose gel at $100 \mathrm{~V}$ for 1 hour, and the gels were stained with ethidium bromide and photographed using a Gel Doc system (BioRad Laboratories, Hercules, CA, USA). All experiments were performed in triplicate.

The mRNA expression level was calculated by quantifying the relative intensity to $\beta$-actin as a reference using ImageJ (National Institutions of Health, MD, USA) software.

\section{Statistical analysis}

The data was analyzed using SPSS (IBM SPSS, version 24, Chicago, IL, USA) and the nonparametric Wilcoxon- test were used for statistical difference between experimental groups. Values with $P<0.05$ were considered to be statistically significant. Graphpad prism version $6.0(\mathrm{GraphPad}$ Software, La Jolla, USA).

\section{RESULTS}

\section{Subjects}

The 27 patients having otitis media were grouped as postauricular skin ( $n=9)$, mastoid mucosa $(n=7)$, inflamed mastoid mucosa $(n=4)$ and middle ear mucosa $(n=7)$, and consisted of 15 males and 12 females, ranging in age from 19 71 years.

\section{Lysozyme genes mRNA expression in otitis media speci- mens}

The expression of lysozyme genes in otitis media specimens were assed using semi-quantitative RT-PCR (Fig. 1). The hLYZ mRNA expression level was very low in the postauricular skin, but high level of hLYZ mRNA expression were detected in mastoid mucosa, inflamed mastoid mucosa and middle ear mucosa compared to that in the postauricular skin $(P<0.001$, relative gene expression level of hLYZ mRNA in mastoid mucosa, middle ear mucosa, postauricular skin, 34.5, 81.4, 4.2, respectively). The expression levels of hLYZ M mRNA and hLYGH mRNA were high both in the inflamed mastoid mucosa and in the middle ear mucosa, but the hLYZH mRNA and hLYGH mRNA were expressed lowly in the mastoid mucosa. No significant expression of hLYZ mRNA, hLYZ M mRNA, and hLYGH mRNA was not detected in the postauricual skin. The expression level of hLYZ mRNA was higher than the expression levels of hLYZ M mRNA and hLYGH mRNA in mastoid mucosa, inflamed mastoid mucosa, and middle ear mucosa $(P<0.05$, relative gene expression level in mastoid mucosa of hLYZ mRNA and hLYZ M mRNA, 35.0, 1.2, respectively). In the mastoid mucosa, the expression levels of hLYZ mRNA, hLYZ M mRNA, and hLYGH mRNA were lower than in the inflamed mastoid mucosa and middle ear mucosa $(P<0.001$, relative gene expression level of $\mathrm{hLYZ}$ $M$ mRNA in mastoid mucosa, inflamed mastoid mucosa, and middle ear mucosa, 5.5, 47.0, 35.0, respectively), but 
Table 1. Primers sequences for semi-quantitative RT-PCR

\begin{tabular}{|c|c|c|c|c|}
\hline Target & Direction & Sequences $\left(5^{\prime}-3^{\prime}\right)$ & Product size (bp) & References \\
\hline \multirow{2}{*}{ AQP0 } & Forward & TGTTCTGCAGGTGGCTATG & \multirow{2}{*}{232} & \multirow{28}{*}{ Seo \& Choi, 2015} \\
\hline & Reverse & TGCTAGGTTTCCTCGGACAG & & \\
\hline \multirow{2}{*}{ AQP1 } & Forward & TCATCAGCATCGGTTCTGC & \multirow{2}{*}{297} & \\
\hline & Reverse & CAAGCGAGTTCCCAGTCAG & & \\
\hline \multirow{2}{*}{ AQP2 } & Forward & TAGCCTTCTCCAGGGCTGT & \multirow{2}{*}{305} & \\
\hline & Reverse & CGTGATCTCATGGAGCAGAG & & \\
\hline \multirow{2}{*}{ AQP3 } & Forward & GTCACTCTGGGCATCCTCAT & \multirow{2}{*}{157} & \\
\hline & Reverse & CTATTCCAGCACCCAAGAAGG & & \\
\hline \multirow{2}{*}{ AQP4 } & Forward & GCCCATCATAGGAGCTGTC & \multirow{2}{*}{209} & \\
\hline & Reverse & GGTCAACGTCAATCACATGC & & \\
\hline \multirow{2}{*}{ AQP5 } & Forward & CCACCCTCATCTTCGTCTTC & \multirow{2}{*}{212} & \\
\hline & Reverse & GTAGAAGAAAGCCCGGAGC & & \\
\hline \multirow{2}{*}{ AQP6 } & Forward & GTGCTGGCTAGGACAGGAAG & \multirow{2}{*}{289} & \\
\hline & Reverse & CTAGGAGAGGGCCTCCAAGT & & \\
\hline \multirow{2}{*}{ AQP7 } & Forward & TGCCACCTACCTTCCTGATC & \multirow{2}{*}{210} & \\
\hline & Reverse & GACGGGTTGATGGCATATCC & & \\
\hline \multirow{2}{*}{ AQP8 } & Forward & TGAGCCTGAATTTGGCAATG & \multirow{2}{*}{226} & \\
\hline & Reverse & CAGCGTGGCAATCACGAGC & & \\
\hline \multirow{2}{*}{ AQP9 } & Forward & CTCAGTGTCATCATGTAGTG & \multirow{2}{*}{336} & \\
\hline & Reverse & GACTATCGTCAAGATGCCG & & \\
\hline \multirow{2}{*}{ AQP10 } & Forward & GCACTGGGATGCTGATTGT & \multirow{2}{*}{190} & \\
\hline & Reverse & CCAGCCACGTAGGTGAAGAG & & \\
\hline \multirow{2}{*}{ AQP11 } & Forward & GACGCTGACGCTCGTCTACT & \multirow{2}{*}{279} & \\
\hline & Reverse & TCTGTGATGACCGCTTTGAG & & \\
\hline \multirow{2}{*}{ AQP12 } & Forward & GAACCTGTTCTACGGCCAGA & \multirow{2}{*}{204} & \\
\hline & Reverse & GTTCCAGGGTCCAGCTACAA & & \\
\hline \multirow{2}{*}{$\beta$-actin } & Forward & ATCATGTTTGAGACCTTCAA & \multirow{2}{*}{318} & \\
\hline & Reverse & CATCTCTTGCTCGAAGTCCA & & \\
\hline hLYZ & Forward & AGGGGTTGCCAGCCTTCAG & 259 & AF 0990291 \\
\hline & Reverse & AGCTGTACTCATGCCGTCCG & 259 & HI__ \\
\hline hIYZ M & Forward & TGTTCGGCATTCTATGCTCTACT & 217 & NC 00001212 \\
\hline 111212101 & Reverse & ATGCCACCCTGTAGAAAAAGATG & 211 & $1 \mathrm{Ne}$ - 000012.12 \\
\hline 1JVCH & Forward & GGAAGATTTGCCTGGAAAGCTA & 126 & \\
\hline nLY Un & Reverse & CAATCGCTTCAATTCCTGACTTA & 156 & $\mathrm{NC}+000002.12$ \\
\hline
\end{tabular}

RT-PCR, reverse-transcription-polymerase chain reaction; AQP, aquaporin; hLYZ, homo sapiens lysozyme; hLYZ M, homo sapiens lysozyme M; hHLGH, homo sapiens lysozyme G like-2.

there was no significant difference in the expression level of hLZY mRNA, hLYZ M and hLYGH mRNA between in the inflamed mastoid mucosa and in the middle ear mucosa.

\section{Aquaporin (AQP) genes mRNA expression in otitis media specimens}

The expression of AQP genes were measured in the otitis media specimens and was shown in Fig. 2. AQP 0 mRNA 


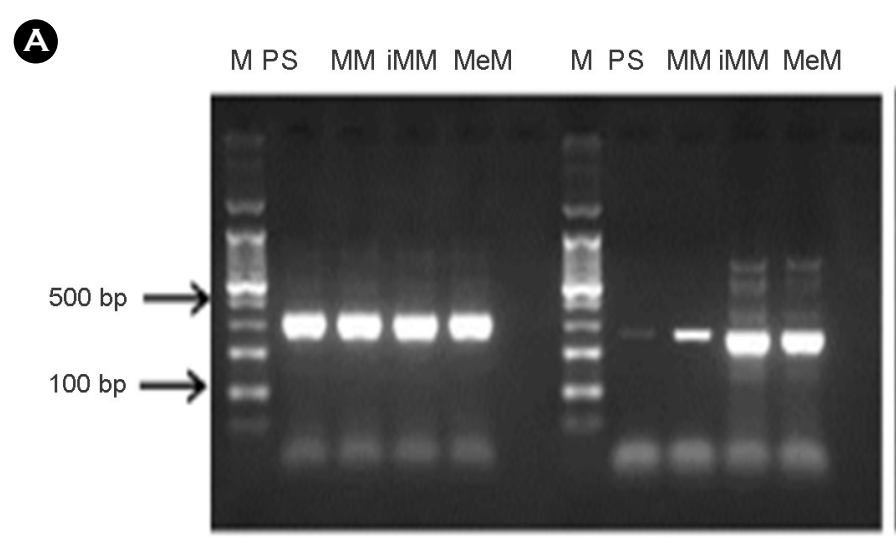

$\beta$-actin

hLYZ

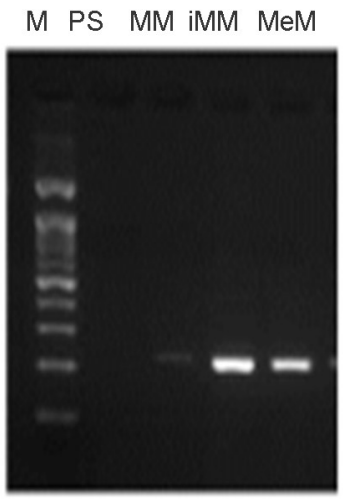

hLYZ M
M PS MM IMM MeM

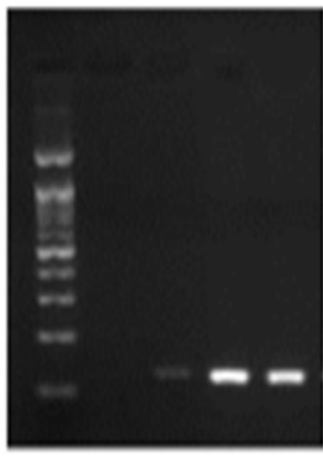

hLYGH

B

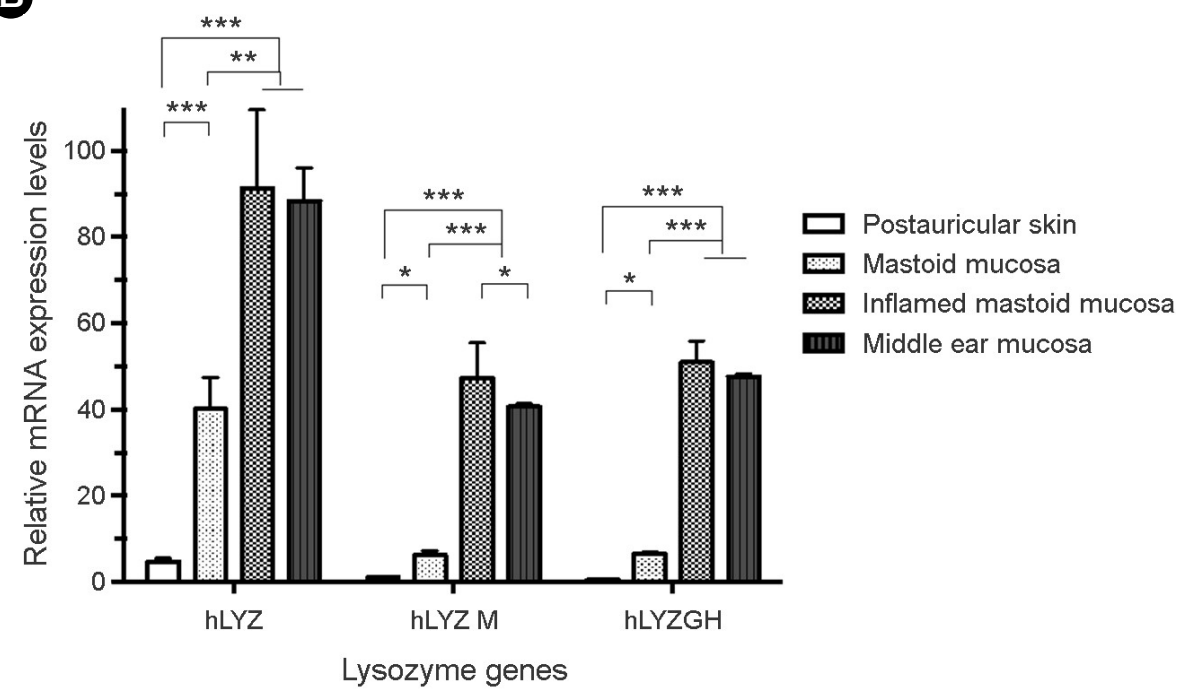

Fig. 1. Expression of lysozyme genes in the middle ear was analyzed by RT-PCR. PCR products were separated by $1.5 \%$ agarose gel electrophoresis, stained with ethidium bromide (A). Results are representatives of three experiments. The mRNA expression level was calculated by quantifying the relative intensity to $\beta$-actin using ImageJ (B). M: 100 bp ladder, PS: Postauricular skin, MM: Mastoid mucosa, iMM: Inflamed mastoid mucosa, MeM: Middle ear mucosa, hLYZ: Homo sapiens lysozyme gene, complete, hLYZ M: Homo sapiens lysozyme M, hLYGH: Homo sapiens lysozyme G-like 2.

was lowly expressed in the inflamed mastoid mucosa and middle ear mucosa and its expression level was faint in mastoid mucosa. The low level of AQP 1 mRNA and AQP 2 mRNA expression were detected only in the inflamed mastoid mucosa. The distinct expression of AQP 3 mRNA was not detected in all four tissues. Additionally, the expression of AQP 5 mRNA, AQP 6 mRNA, and AQP 7 mRNA was dim in the inflamed mastoid mucosa. AQP 8 mRNA, AQP 9 mRNA, AQP 10 mRNA, AQP 11 mRNA and AQP 12 mRNA were highly expressed in the inflamed mastoid mucosa and middle ear mucosa compared to their expression levels in the postauricular skin and mastoid mucosa $(P<0.01$, relative gene expression level of AQP 8 mRNA in the inflamed mastoid mucosa, middle ear mucosa, postauricular skin, 20.0, 16.3, 0.3, respectively). On the other side, the expression level of AQP 8, AQP 9 mRNA, AQP 10 mRNA, AQP 11 mRNA and AQP 12 mRNA were low in the mastoid mucosa, but were not detectable in the postauricular skin.

There was no detectable expression in all AQP mRNAs in the postauricular skin. In the mastoid mucosa, AQP 8 


\section{(4)}

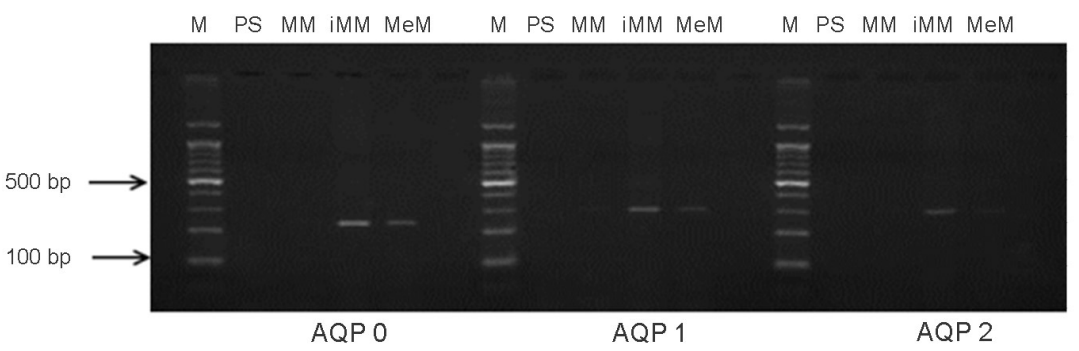

B

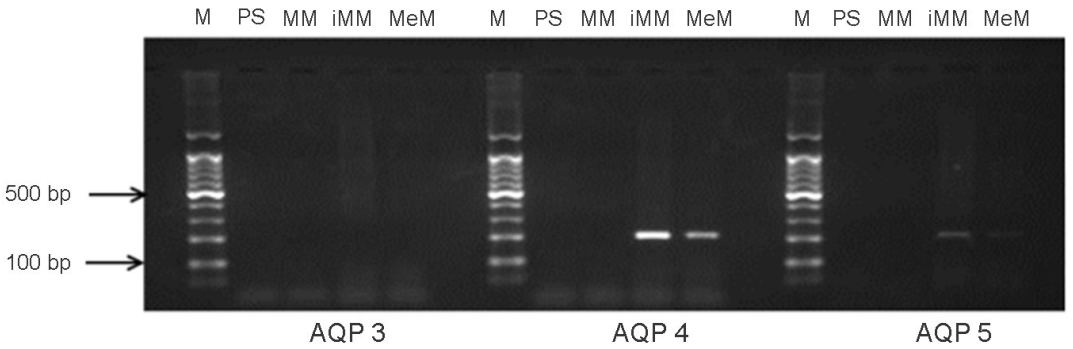

C

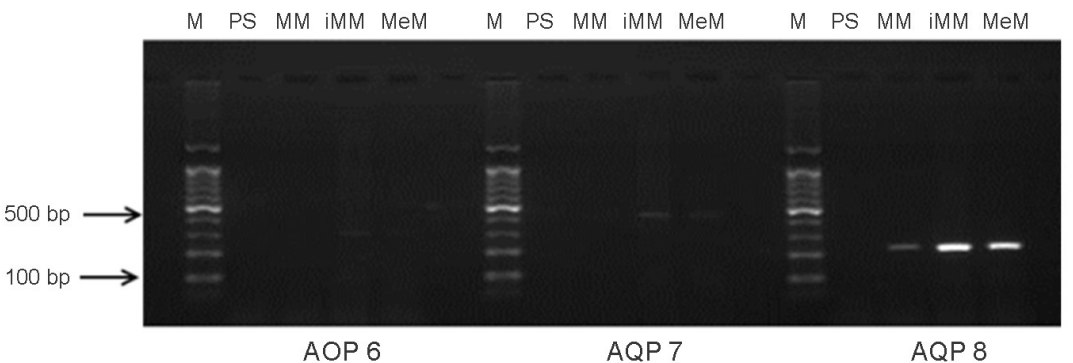

D

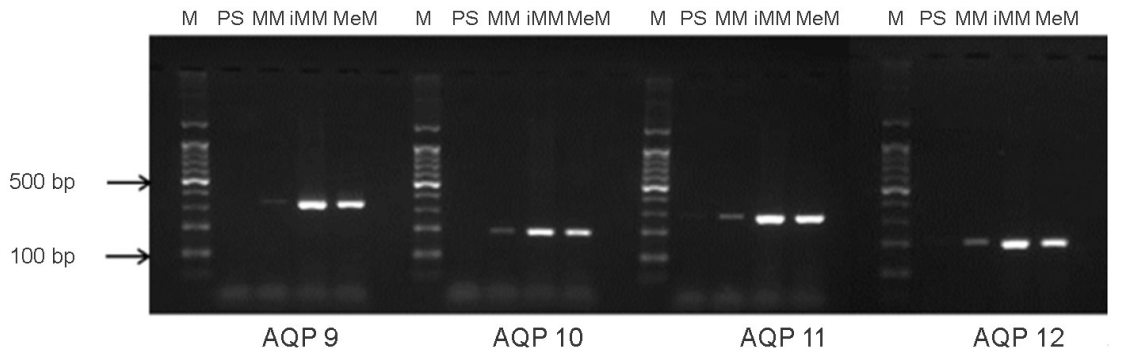

E

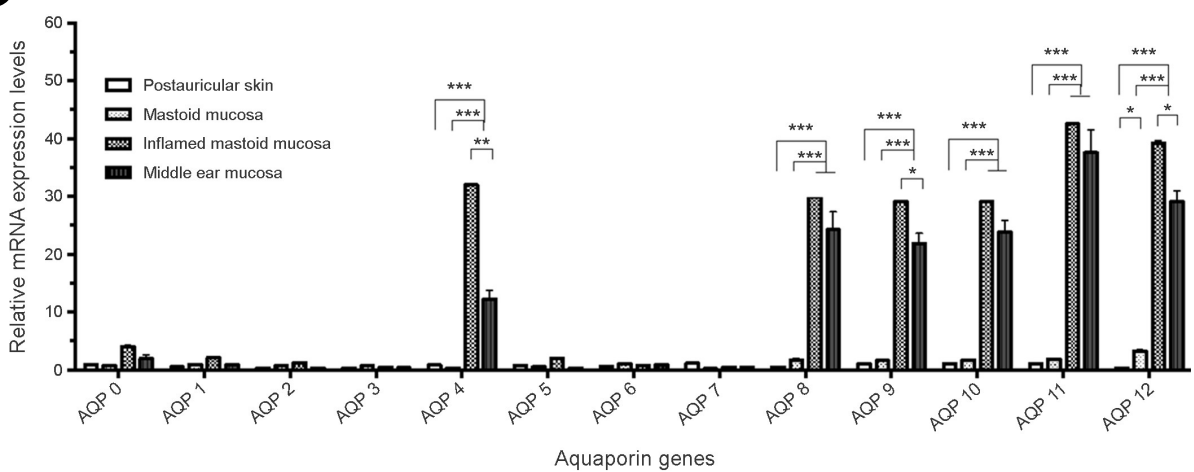

Fig. 2. Expression of AQP genes in the middle ear tissue was analyzed by RT-PCR. PCR products were separated by $1.5 \%$ agarose gel electrophoresis, stained with ethidium bromide (A-D). Results are representative of three experiments. The mRNA expression level was calculated by quantifying the relative intensity to $\beta$-actin using ImageJ (E). M: 100bp DNA ladder, PS: Postauricular skin, MM: Mastoid mucosa, iMM: Inflamed mastoid mucosa, MeM: Middle ear mucosa; AQP: Aquaporin. 
mRNA, AQP 9 mRNA, AQP 10 mRNA, AQP 11, and AQP 12 mRNA were weakly expressed, and the expression level of AQP 12 mRNA was highest. In the inflamed mastoid mucosa, expression of AQP 0, AQP 1, AQP 2, AQP 4, AQP 5, AQP 6, AQP 7, AQP 8, AQP 9, AQP 10, AQP 11 and AQP 12 mRNA except AQP 3 mRNA were detected. The expression level of AQP 0 mRNA, AQP 1 mRNA, AQP 2 mRNA, AQP 5 mRNA, AQP 6 mRNA and AQP 7 mRNA were weak, but AQP 4 mRNA, AQP 8 mRNA, AQP 9 mRNA, AQP 10 mRNA, AQP 11 mRNA and AQP 12 mRNA were expressed very highly. In the middle ear mucosa, the expression of AQP 0 mRNA, AQP 1 mRNA, AQP 4 mRNA, AQP 5 mRNA, AQP 7 mRNA, AQP 8 mRNA, AQP 9 mRNA, AQP 10 mRNA, AQP 11 mRNA and AQP 12 mRNA were detected, but the expression of AQP 2 mRNA, AQP 3 mRNA and AQP 6 mRNA were not examined. The expression level of AQP 0 mRNA, AQP 1 mRNA, AQP 5 mRNA, and AQP 7 mRNA were expressed very dim, but the expression level of AQP 4 mRNA, AQP 8 mRNA, AQP 9 mRNA, AQP 10 mRNA, AQP 11 mRNA and AQP 12 was fairly high.

\section{DISCUSSION}

In the present study, lysozyme and AQPs were investigated to reveal the possible association with immune response in the middle ear. hLYZ M gene and hLYGH gene were expressed highly in the inflamed mastoid mucosa compared to the normal mastoid tissue. These results were consistent with previous report that hLYZ $\mathrm{M}$ has bacteriacidal activity, especially against gram-negative bacteria (Markart et al., 2004). In addition, the bactericidal activity of hLYGH was also reported previously (Giacemello et al., 2006; Kim, 2005). These might indicate that hLYZ M and hLYGH might be strongly related with inflammatory status as lysozyme in the mucosal membrane of middle ear, which might contribute to immunity of middle ear from bacterial infection.

AQPs are water channel that play a role in the intercellular water movement in the living tissues and have been regarded as potential factors of immunity. In the present study, aquaporin genes were examined to reveal their relevance with the immunity of middle ear. Of the $13 \mathrm{AQP}$ genes, all tested AQP genes except AQP 3 gene were expressed in the tissue of middle ear. The expression levels of AQP 0, AQP 2, AQP 5, AQP 6 and AQP 7 gene were weak in the otitis media, which suggest that these genes might be possibly associated with inflammatory response of the otitis media. Among them, AQP 4, AQP 8, AQP 9, AQP 10, AQP 11, and AQP 12 gene were highly expressed in the inflamed mastoid mucosa and middle ear mucosa, and their expression level in the inflamed mastoid mucosa was higher than that in the mastoid mucosa $(P<0.001)$. These results suggest that these AQP genes might be related with inflammatory responses, which imply their contribution to immunity in the middle ear. The high level of expression of AQP 9 gene supposed to be related with the accumulation of lymphocytes or neutrophils in the inflammatory site of mastoid mucosa, which could be analogize from the previous reports that AQP 9 facilitate immune response in lymphocytes and neutrophils (Rojek et al., 2007; Moniagal et al., 2007). The AQP 4 gene had been a target of autoimmunity in the neuromylelitis optica (Lennon et al., 2005), but there was rare report that AQP 4 is related with inflammatory response. Therefore, it might be a novel discovery that AQP 4 has a potential factor of the inflammatory response in the middle ear. The other $\mathrm{AQP}$ genes, $\mathrm{AQP} 8$, AQP 10, AQP 11, and AQP 12, could be new factors as AQP 4 in the immunity of otitis media. In the future study, it would be necessary to investigate the mechanism of AQP genes including hLYZ, hLYZ M, and hLYGH, in the inflammation of the otitis media.

In the present study, a large number of patient subjects having otitis media were not enrolled, and especially, healthy subjects could not be enrolled by prohibition of Institutional Ethical Committee. Nevertheless, involvement of lysozyme genes and AQP genes in the otitis media could be statistically investigated.

In conclusion, lysozyme genes, hLYZ, hLYZ $\mathrm{M}$ and hLYGH gene were highly expressed in the inflamed mastoid mucosa. The expression of most of AQP genes were examined in the tissue of otitis media, and especially six AQP genes were highly expressed in the inflamed mastoid mucosa. These suggest that Lysozyme genes and AQP genes might be associated with immunity of otitis media. 


\section{ACKNOWLEDGEMENTS}

This work was supported by the fund of Research of Hanmi Pharmacy Corporation (Seoul, Republic of Korea).

\section{CONFLICT OF INTEREST}

The authors have no conflicts of interest to disclose.

\section{REFERENCES}

Agre P, Preston GM, Smith BL, Jung JS, Raina S, Moon C, Guggino WB, Nielsen S. Aquaporin CHIP: the archetypal molecular water channel. American Journal of Physiology. 1993. 265: 463-476.

Denker BM, Smith BL, Kuhajda FP, Agre P. Identification purification, and partial characterization of a novel $\mathrm{Mr} 28,000$ integral membrane protein from erythrocytes and renal tubules. The Journal of Biological Chemistry. 1988. 263: 15634-15642.

Dibas AI, Mia AJ, Yorio T. Aquaporins (water channels): role in vasopressin-activated water transport. Proceedings of the Society for Experimental Biology and Medicine. 1998. 219: 183-199.

Elkjaer ML, Nejsum LN, Gresz V, Kwon TH, Jensen UB, Frøkiaer J, Nielsen S. Immunolocalization of aquaporin-8 in rat kidney, gastrointestinal tract, testis, and airways. American Journal of Physiology-Renal Physiology. 2001. 281: 1047-1057.

Ganz T. Antimicrobial polypeptides. journal of leukocyte biology. 2004. $75: 34-38$

Giacomello E, Marchini D, Rasotto MB. A male sexually dimorphic trait provides antimicrobials to eggs in blenny fish. Biology Letters. 2006. 2: 330-333.

Gorelick DA, Praetorius J, Tsunenari T, Nielsen S, Agre P. Aquaporin -11: A channel protein lacking apparent transport function expressed in brain. BMC Biochemistry. 2006. 7:14

Ishibashi K, Kuwahara M, Gu Y, Kageyama Y, Tohsaka A, Suzuki F, Marumo F, Sasaki S. Cloning and functional expression of a new water channel abundantly expressed in the testis permeable to water, glycerol, and urea. The Journal of Biological Chemistry. 1997. 272: 20782-20786.

Itoh T, Rai T, Kuwahara M, Ko SB, Uchida S, Sasaki S, Ishibashi $\mathrm{K}$. Identification of a novel aquaporin, $\mathrm{AQP} 12$, expressed in pancreatic acinar cells. Biochemical Biophysical Research Communications. 2005. 330: 832-838

Kim AB. Antimicrobial peptides: pore formers or metabolic inhibitors in bacteria?. Nature Review Microbiology. 2005. 3:
238-250

Klein JO. The burden of otitis media. Vaccine. 2000. 19: S2-S8.

Konstan MW, Cheng PW, Boat TF. A comparative study of lysozyme and its secretion by tracheal epithelium. Experimental Lung Research. 1982. 3: 175-181.

Lee MD, Bhaktai KY, Rainai S, Yonescu R, Griffin CA, Copeland NG, Gilbert DJ, Jenkins NA, Preston GM, Agre P. The human Aquaporin-5 gene. Molecular characterization and chromosomal localization. The Journal of Biological Chemistry. 1996 271: 8599-8604

Lennon VA, Kryzer TJ, Pittock SJ, Verkman AS, Hinson SR. IgG marker of optic-spinal multiple sclerosis binds to the aquaporin4 water channel. The Journal of Experimental Medicine. 2005 202: 473-477.

Li H, Kamiie J, Morishita Y, Yoshida Y, Yaoita E, Ishibashi K, Yamamoto T. Expression and localization of two isoforms of AQP10 in human small intestine. Biology of the Cell. 2005. 97: 823-829.

Lim DJ, Chun YM, Lee HY, Moon SK, Chang KH, Li JD, Andalibi A. Cell biology of tubotympanum in relation to pathogenesis of otitis media-a review. Vaccine. 2000. 19: S17-25.

Markart P, Faust N, Graf T, Na CL, Weaver TE, Akinbi HT. Comparison of the microbicidal and muramidase activities of mouse lysozyme M and P. Biochemical Journal. 2004. 380: 385-392.

Moniagal CS, Watanabe S, Honda T, Nielsen S, Chikuma MH Aquaporin-9-expressing neutrophils are required for the establishment of contact hypersensitivity. Scientific Reports. 2015 5: 5319 .

Nemeth-Cahalan KL, Clemens DM, Hall JE. Regulation of AQP 0 water permeability is enhanced by cooperativity. Journal of General Physiology. 2013. 141: 287-295.

Park K, Park HJ, Choung YH Song JW. Distribution of lysozyme and lactoferrin-secreting in eustachian tube of normal BALB/c mouse. Korean Journal of Otolaryngology-Head and Neck Surgery. 1992. 42: 811-815.

Prager EM, Jolles P. Animal lysozymes a and g: an overview. Exs. 1996. 75: 9-31.

Rojek AM, Skowronski MT, Fu"chtbauer EM, Fu“chtbauer A Fenton RA, Agre Peter, Frøkiær J, Nielsen S. Defective glycerol metabolism in aquaporin 9 (AQP9) knockout mice. Proceedings of the National Academy of Science of United States of America. 2007. 104: 3609-3614.

Rovers MM, Schilder AG, Zielhuis GA, Rosenfeld RM. Otitis media. Lancet. 2004. 363: 465-473.

Seo YJ, Choi JY. Expression and localization of aquaporin water 
channels in human middle ear epithelium. Otology \& Neurology. 2015. 36: 1284-1289.

Saitoa T, Tanaka Y, Morishitab Y, Ishibashia K. Proteomic analysis of AQP11-null kidney: Proximal tubular type polycystic kidney disease. Biochemistry Biophysics Reports. 2018. 13: 17-21.

Sasaki S, Ishibashi K, Marumo F. Aquaporin-2 and -3: representatives of two subgroups of the aquaporin family colocalized in the kidney collecting duct. Annual Review Physiology. 1998.
60: $199-220$

https://doi.org/10.15616/BSL.2018.24.2.116

Cite this article as: Kang $\mathrm{SH}$, Lim DJ, Kim BH, Rhu MS, Kang SS. Expression of Lysozyme and Aquaporins mRNA in Otitis Media. Biomedical Science Letters. 2018. 24: 116-124. 